\title{
TERAJU
}

Teraju: Jurnal Syariah dan Hukum

Volume 02 Nomor 01, Maret 2020

DOI: https://doi.org/10.35961/teraju.v2i01.89

\section{Kepemimpinan Wanita Perspektif Hukum Islam}

\author{
Mhd. Abror \\ STAIN Sultan Abdurrahman Kepulauan Riau \\ mbd_abror@stainkepri.ac.id
}

\begin{abstract}
Abstrak
Pembahasan ini hendak menelaah lebih dalam tentang kepemimpinan wanita di tinjau dari aspek hukum Islam. Hal ini dimaksudkan agar mendapatkan gambaran yang jelas, bagaimana sebenarnya tuntunan syariah tentang kepemimpinan perempuan serta batas-batasnya. Penelitian ini merupakan jenis penelitian kepustakaan (library research), yaitu suatu penelitian yang data-datanya berasal dari literatur-literatur yang terkait dengan obyek penelitian, kemudian dianalisis muatan isinya. Dari kajian ini menegaskan bahwa, terdapat kesepakatan ulama fiqih (ijmak) dari keempat madzhab dan lainnya, salaf dan kontemporer, bahwa perempuan tidak boleh menduduki jabatan al-khilafah al-ammah atau al-imamah al-udzma. Namun, tidak dipungkiri defenisi kedua istilah ini memiliki perbedaan pandangan. Mayoritas memaknai kata al-khilafah al-ammah atau al-imamah al-udzma sebagai kepala negara yang membawahi wilayah Islam di seluruh dunia seperti yang terjadi pada zaman empat khalifah pertama (khulafaur rasyidin), masa khilafah Abbasiyah dan Umayyah. Pada umumnya Ulama fiqih klasik melarang perempuan menjadi hakim, kecuali Ibnu Hazm, Ibnu Jarir At-Tabari dan imam Abu Hanifah mereka membolehkan perempuan menduduki posisi apapun. Pandangan ketiga ulama terakhir ini menjadi salah satu alasan ulama kontemporer atas bolehnya wanita menjabat posisi apapun asal memenuhi syarat.
\end{abstract}

Kata Kunci: Wanita, Kepepimpinan Wanita, Pemimpin.

\begin{abstract}
This discussion would like to examine deeper about women's leadership in terms of aspects of sharia law. This is intended to get a clear picture of how the actual guidance of sharia about women's leadership and its limits. This research is a type of library research, which is a study whose data comes from the literature related to the research object, then
\end{abstract}


analyzed its contents. From this study, it is confirmed that there is agreement on the scholars of figh (ijmak) from the four schools of thought and others, salaf and contemporary, that women should not occupy the positions of al-khilafah al-ammah or al-Imamah al-udzma. However, no doubt the definition of these two terms have different views. The majority interpret the words al-khilafah al-ammah or al-Imamah aludzma as heads of state in charge of Islamic regions throughout the world as happened in the days of the first four caliphs (khulafaur rashidin), the Abbasid and Umayyad caliphates. In general, classical figh scholars forbid women from becoming judges, except for Ibn Hazm, Ibn Jarir At-Tabari and their Imam Abu Hanifah allowing women to occupy any position. The view of the last three scholars is one of the reasons why contemporary scholars are allowed to hold any position as long as they meet the conditions.

Keywords: Women, Women's Leadership, Islamic Law

\section{Pendahuluan}

Wacana tentang kemepimpinan perempuan selalu menjadi perbincangan hangat, baik di kalangan Internasional, maupun di Indonesia. Di Indonesia perbincangan tentang kebolehan atau tidaknya seorang perempuan menjadi pejabat tinggi, atau pemimpin di suatu negara menjadi perbincangan hangat barubaru ini. Ini mulai hangat pasca era Reformasi, yaitu semenjak lengsernya presiden Indonesia Bapak Abdurrahman Wahid pada tahun 2001 dan digantikan oleh Ibu Megawati Soekarnoputri yang menjadi presiden wanita pertama di Indonesia.

Pembahasan seputar kepemimpinan Perempuan merupakan salah satu kajian yang tak pernah surut dalam dunia keilmuan. Walaupun dalam banyak seminar, diskusi sudah dan sering dibahas berkali-kali, namun selalu ada upaya penyegaran dan pemikiran untuk menbahas kajian tersebut.

Dalam sejarah Islam, kedudukan seorang wanita pada masa Nabi Muhammad SAW. Tidak terpaku hanya sebagai istri, pendamping, dan pelengkap laki-laki saja, namun juga dipandang sebagai manusia yang memiliki kedudukan yang setara dalam hak dan kewajiban dengan manusia lain di hadapan Allah Swt. Misalnya mulai dari Siti Aisyah (ummul mukminin) menjadi pemimpin perang Jamal, Ummu Hani, al-Syifâ sebagai seorang perempuan yang pintar menulis dan ditugaskan oleh khalifah Umar ibn alKhaththâb menjadi petugas yang mengurus pasar kota Madinah, dan lainlain. ${ }^{1}$

Dalam permasalahan kepemimpinan, agama Islam telah memberikan hak kepada wanita sebagaimana yang diberikan Islam kepada laki-laki, sama halnya juga islam telah memberikan kewajiban kepada perempuan sebagaimana yang dipikulkan Islam kepada laki-laki, kecuali ada kewajiban dan hak yang memang telah dikhususkan Islam untuk kaum laki-laki berdasarkan dalil-dalil syara', oleh karena itu sangat menarik

1 Muhammad al-Ghazâlî, Al-Islâm wa alThâqah al-Mu"atthalah (Kairo: Dâr al-Kutub alHadîtsah, 1964), h.138. 
dilakukan pembahasan ini. Tulisan ini akan memfokuskan pembahasan dari aspek hukum syariah, suatu sudut pandang yang paling menjadi perhatian umat Islam secara umum.

\section{Pembahasan}

A. Pengertian Kepemimpinan

Kepemimpinan dalam pengertian umum adalah suatu proses ketika seseorang memimpin, membimbing, mempengaruhi, atau mengontrol pikiran, perasaan dan tingkah laku orang lain ${ }^{2}$. Dalam alQur'an paling tidak kita menemukan tiga kata yang digunakan ketika berbicara tentang kepemimpinan, yaitu :

Pertama, kata Khalifah, yaitu dalam surah al-Baqoroh ayat 30 :

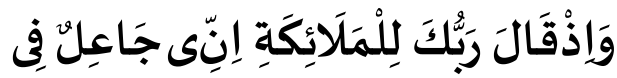
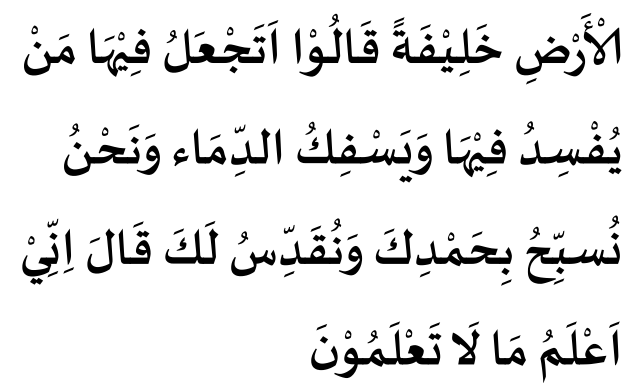

Artinya : Ingatlab ketika Tuhanmu (Allah SWT) berfirman kepada para Malaikat: "Sesunggubnya Aku bendak menciptakan seorang khalifah di muka bumi". Mereka berkata: kenapa Engkan hendak menjadikan khalifah di bumi itu orang-orang yang akan melakukan kerusakan padanya dan akan menumpabkan darah, padahal kami senantiasana bertasbih dengan memuji-Mu

2 Khatib Pahlawan Kayo, Kepemimpinan Islam dan Dakwah, Sinar Grafika Offset, Jakarta, 2005, h.7 dan mensucikan-Mu? Allab SWT berfirman : Sesunggubnya Aku lebih mengetabui apa yang tidak kalian ketabui.

Kedua ialah kata "Imam" dalam surah al- Baqoroh ayat 124 yang berbunyi :

وَإِذِ ابْتَلَى ابْرَ اهِيْمَ رَبَّهُ بِكَلِمَاتٍ

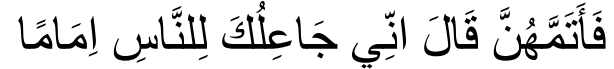

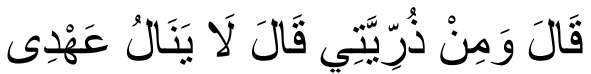
الظَّالِمِيْنَ

Artinya: Dan (ingatlah), ketika Ibrabim diuji Tubannya dengan beberapa kalimat (perintah dan larangan), lalu Ibrabim menunaikannya. Allah berfirman: sesunggubnya aku akan menjadikan kamu imam untuk selurub umat manusia. Ibrahim berkata: "(Dan saya mohon juga) dari keturunanku". Allah SWT berfirman : Janji-Ku ini tidak akan mengenai orangorang yang dzalim.

Ketiga adalah kata Ulil Amr, yaitu dalam surah an-Nisa ayat 59:

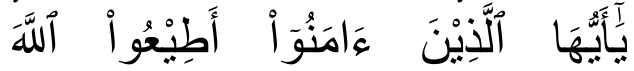

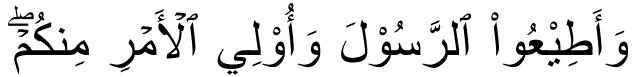

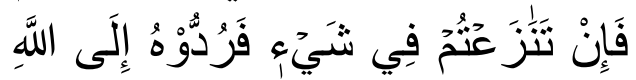

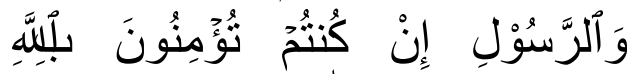

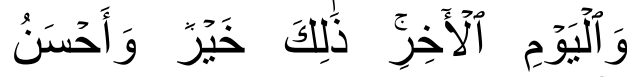
تَأَوْيًَا

Artinya: Hai orang-orang yang beriman, taatilah Allah SWT dan taatilab Rosul (Nya), dan ulil amri di antara kamu. Kemudian jika kamu berbeda pendapat tentang sesuatu hal, maka kembalikanlah ia kepada Allah SWT (Al Quran) dan Rosul (sunnabnya), jika kamu benar-benar beriman kepada Allah SWT dan bari Akbirat yang demikian itu lebih utama dan lebih baik akibatnya bagimu.

Kata khalifah berasal dari akar kata yang pada mulanya berarti 
dibelakang, dan oleh karena itu kita sering menyebutnya dengan pengganti, karena yang menggantikan selalu berada atau datang dari belakang atau sesudah yang digantikannya. Dari satu sisi kata ini menegaskan kedudukan pemimpin hendaknya beada di belakang, untuk mengawasi dan membimbing yang dipimpinnya, bagaikan para pengembala. Tujuan pengawasan ini adalah untuk memelihara serta mengantar gembalaannya menuju arah dan tujuan penciptaannya ${ }^{3}$.

Kata Imam berasal dari kata amma-yаuтmи dalam arti menuju, menumpu, dan meneladani. Ibu, dinamakan Ummi karena anakanaknya selalu menuju kepadanya. Depan dinamakan amama karena mata tertuju kepadanya sebab dia berada di depan. Dengsn demikisn seorang imam atau pemimpin bukan hanya mampu menunjukkan jalan meraih cita-cita masyarakatnya, tetapi juga dapat mengantar mereka ke pintu gerbang kebahagiaan. Seorang pemimpin tidak hanya menunjukkan, tetapi jiga mampu memberi contoh aktualisasi, sama halnya imam dalam shalat, memberi contah agar diteladani oleh makmumnya ${ }^{4}$.

Kata Amr menggunakan kata yang dapat berarti subjek dan juga objek. Ini berarti Amr atau pemimpin dalam kedudukannya sebagai subjek adalah pemilik wewenang memerintah, sedangkan dalam kedudukannya sebagai objek, maka dia adlah yang diperintah, dalam hal ini oleh siapa yang dipimimpinnya. Ini mengisyaratkan, bahwa Amr tidak boleh bertindak sewenang-wenang, tetapi harus memperhatikan "perintah", yakni kehendak dan aspirasi dari siapa yang dipimpinnya ${ }^{5}$.

Dengan demikian, pemimpin adalah orang orang yang dapat mempengaruhi orang lain atau pengikut-pengikutnya sehingga orang lain tersebut mengikuti ataupun bertingkah laku sebagaimana yang dikehendaki oleh pemimpin tersebut.

Dapat juga kita lihat, bahwa ciri seorang pemimpin adalah di depan menjadi panutan, dan pada kesempatan di belakang untuk mendorong sekaligus menuntun kearah yang dituju oleh yang dipimpinnya.

B. Syarat-syarat Menjadi Seorang Pemimpin Imam al-Mawardi menjelaskan bahwa seoarang pemimpin itu harus memiliki sayarat yang khusus, yaitu: 1) Adil, 2) Ilmu pengetahuan yang mantap tentang agama, 3) Kesehatan jasmani dan rohani, 4) Keberanian, 5) Kesanggupan menjalankan jihad terhadap musuh-musuh negara, dan 6) Keturunan quraish ${ }^{6}$.

Dalam literatur lain, disebutkan bahwa syarat seorang pemimpin adalah dari kalngan laki-

3 M. Quraish Shihab, Tafsir Al- Misbab: Pesan, Kesan dan Keserasian Alquran, Jakarta: Lentera Hati, 2006, h.386

${ }^{4}$ Ibid, h. 387

\footnotetext{
${ }^{5}$ Ibid, hal. 388

6 Mawardi, Al-Abkam As-Sulthaniyah (Terj), Bekasi, 2012, h. 3
} 
laki, ini berlandaskan firman Allah yang berbunyi :

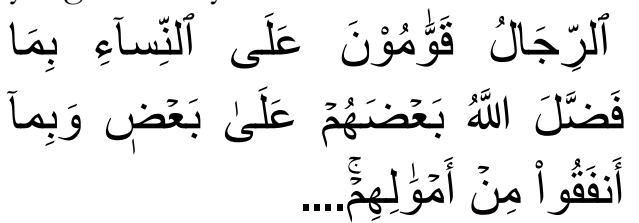

Artinya: Kaum laki-laki itu adalah pemimpin bagi kaum wanita, oleh karena Allah telah melebibkan sebahagian mereka (laki-laki) atas sebahagian yang lain (wanita), dan karena mereka (laki-laki) telah menafkabkean sebagian dari harta merek....

C. Wanita Dalam Pandangan Islam

Ada beberapa pembahasan terkait dengan wanita pandangan Islam: 1. Hak-hak Wanita dalam Bidang Politik

Salah satu ayat yang sering kali dikemukakan oleh para pemikir islam dalam kaitan dengan hak-hak politik wanita adalah surah atTaubah ayat 71 yang berbunyi :

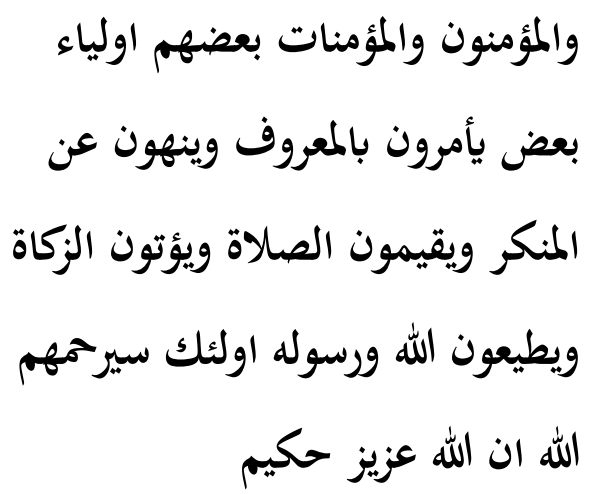

Artinya : Dan orang-orang yang beriman, lelaki dan perempuan, sebagian mereka menjadi penolong (pemimpin) bagi sebagian yang lainnya. Mereka mengajak agar melaksanakan yang ma'ruf dan meninggalkan atau mencegah yang munkar dan melaksanakan shalat dan

${ }^{7}$ QS. An-Nisa : 34 membayar zakat dan mereka mentaati Allab SWT dan Rasul-Nya (Mubammad SAW). Mereka itu akan mendapatkan rahmat dari Allah SWT; sesunggubnya Allab SWT itu Maha Perkasa lagi Maha Bijaksana.

Secara umum, ayat di atas dipahami sebagai gambaran tentang kewajiban melakukan kerja sama antara lelaki dan wanita dalam berbagai bidang kehidupan yang dilukiskan dengan kalimat menyuruh untuk mengerjakan yang makruf dan mencegah yang mungkar. Dan dalam ayat ini juga menjelaskan, bahwa perempuan memilki hak dan kewajiban yang sama dalam kehidupan ini.

2. Hak Wanita dalam Memilih Pekerjaan

Secara singkat, dapat dikemukakan rurmusan menyangkut pekerjaan wanita, yaitu wanita mempunyai hak untuk bekerja, selama pekerjaan tersebut membutuhkannya atau selama mereka membutuhkan pekerjaan tersebut sesuai dengan aturan yang berlaku. Pekerjaan wanita pada masa Nabi sangat beragam, sampaisampai mereka terlibat secara langsung dalam peperanganpeperangan, bahu-membahu dengan kaum lelaki, diantaranya adalah : Ummu Salamah (istri Nabi), Shafiyah, Lailah al-Gaffariyah, Ummu Sinam al-Aslamiyah, dan lain-lain sebagainya ${ }^{8}$.

Selain itu, wanita pada masa Nabi juga aktif dibidang lain, seperti perias pengantin yaitu Ummu Salim

${ }^{8}$ Ibid, h. 11 
binti Malhanyang merias istri Rasulullah, dan ada juga yang menjadi perawat, bidan dan lain-lain sebagainya.

Dalam bidang perdagangan ada juga, seperti Khadijah binti Khuwailid, istri Nabi yang pertama, tercatat sebagai seorang yang sangat sukses dai bidang perdagangan. Demikian pula Qilat binti Bani Ammar yang tercatat sebagai seorang wanita yang pernah datang kepada Nabi untuk meminta petunjuk-petunjuk tentang jual beli.

3. Fitrah dan Kodrat Wanita

Fitrah menurut bahasa berasal dari kata fathara yang artinya menciptakan dan suci. Menurut istilah fitrah adalah karektaristik bawaan yang melekat pada diri manusia sejak ia dilahirkan. Kerakteristik bawaan adalah naluri ataupun insting serta potensi yang mendorong untuk dapat memenuhi kebutuhan hidup. Sedangkan menurut syari at islam, fitrah manusia pada dasarnya adalah suci. ${ }^{\text {? }}$

Fitrah antara laki-laki dan wanita pada dasarnya adalah sama, yang menjadi pembeda dalah kodratnya. Kodrat wanita yang palin kuat adalah, mengandung, melahirkan, dan menyusui. Terkait urusan dapur, kebersihan rumah, mengasuh anak, dan lain-lain sebagainya adalah bentuk usaha yang pada dasarnya bisa dilakukan oleh kaum laki-laki. Akan tetapi, jika terjadi pembagian peran, hendaknya

9 Anna Mariana, Ketika Allab Lebih Menyayangi Wanita, Kawan Pustaka, Bandung, 2011, h. 34 dilakukan atau dibicarakan dengan matang. Karena dalam kodrat wanita sebenarnya memiliki misi yang amat mulia, yaitu membuka tabir bahwa Allah SWT, ternyata lebih menyayangi wanita. Justru dengan kodrat itulah menjadikan sosok wanita lebih tinggi nilainya di mata sang pencipta.

D. Pembagian Wilayah

Dalam kaidah bahasa Arab level kepemimpinan itu disebut al wilayah yang secara etimologis bermakna suatu negara yang diatur oleh seorang kepala pemerintahan. Al-Wilayah juga bermakna pejabat atau pemimpin dari negara itu sendiri. Secara istilah al-wilayah terbagi menjadi tiga yaitu : 1) al-wilayah aludzma al-kubro, 2) al-wilayah al-ammah bermakna "jabatan yang memiliki otoritas untuk melaksanakan tiga jabatan yaitu eksekutif (tanfidriyah), yudikatif (qadhaiyah) dan legislatif (tashri'iyab). 3) al-wilayah as-sughro alkhassah.

al-Wilayah al-Udzma al-Kubro maksudnya adalah wilayah suatu negara yang dipimpin oleh seorang kepala pemerintahan yang saat ini sering disebut dengan presiden, kanselir, raja atau perdana menteri. Namun, penafsiran dalam mendefinisikan kata al-wilayah aludzma al-kubro dan al-wilayah as-sughro memiliki berbagai perbedaan. Ada juga mengakatan bahwa yang dimaksud dengan al-wilayah al-kubro ialah kekuasaan khilafah yang mencakup semua negara-negara Islam di seluruh dunia dan pemimpin atau 
menguasanya dinamakan dengan alimamah al-udzma. ${ }^{10}$

Dalam pendapat ini, maka sebenarnya al-khilafah al-ammah atau alimam al-udzma yang menjadi pemimpin / penguasa tertinggi dalam al-wilayah al-udzma pada dasarnya tidak ada. Saat ini yang ada hanyalah kepala negara dalam level al-wilayah as-sughra. Pendapat ini diikuti oleh ulama-ulama kontemporer seperti Tantawi, Ali Jum 'ah dan imam Yusuf Qardhawi. Sedangkan al-wilayah as-sughro hanya mencakup pada satu negara Islam saja di antara negara-negara Islam yang lainnya.

Dalam konteks pemahaman seperti di atas, Yusuf Qardawi menyatakan:

"Ulama fiqib telah sepakat babwa perempuan tidak boleb menduduki jabatan Al-Imamah Al-Udrma atau AlKhilafah al-Ammah yaitu pemimpin atau penguasa umat Islam di seluruh dunia. namun apakah kepala negara (pemimpin) dalam level regional dan lokal saat ini termasuk kedalam kategori alkbilafah atau sama dengan kepala daerah pada zaman dabulu?"11.

Terlepas dari itu, AlMawardi dalam Al-Abkam AsSultaniyyah membagi kekusaan alwilayah al-ammah yang berada di bawah kepala negara (al-wilayah alkubro) ke dalam empat bagian:

Pertama, orang yang kekuasaannya umum dalam urusan umum. Mereka ialah menteri yang

10 Abarizan, Wanita, Politik Dan Hokum, LPP UIN Suska, Pekanbaru, 2012, h. 104

11 Yusuf Al-Qordhawi, Fiqih Negara, Robbani Press, Jakarta, 1997, h. 50 memiliki bertanggung jawab untuk seluruh urusan tanpa ada kekhususan. Kedua, pejabat yang kekuasaannya umum dalam tugas-tugas khusus. Mereka ialah para pemimpin di kota atau di daerah yang memiliki tugas yang dikhususkan untuk mereka yang merupakan umum untuk semua urusan. Ketiga adalah orang-orang yang memiliki kekuasaan khusus namun memiliki tugas untuk urusan yang umum. Mereka seperti hakim, komandan tentara, penarik pajak dan zakat. Keempat, pejabat yang tugasnya khusus untuk urusan khusus. Seperti hakim kota atau daerah, penarik pejak atau zakat, penegak hukum, dan lain-lain. Karena masing-masing memiliki pengawasan khusus dan tugas khusus.

E. Titik Kontroversi Kepemimpinan Wanita Munculnya pendapat yang berbeda tentang kepemimpinan wanita dalam Islam bersumber dari perbedaan pendapat para ulama dalam menafsirkan sejumlah teks baik dari Al-Quran maupun hadits Nabi Muhammad SAW. Ada sejumlah nash yang menjadi dasar perbedaan penafsiran oleh para ulama antara lain:

1. Surah An-Nisa ayat 34 :

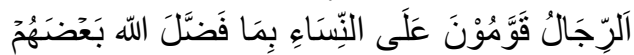

Artinya: Kaum laki-laki itu ialah sebagai pemimpin bagi kaum perempuan, dikarenakan Allah telah melebibkan sebagian mereka kaum laki-laki atas sebahagian yang lain yaitu kaum wanita..... 
2. Surah al-Ahzab ayat 33 :

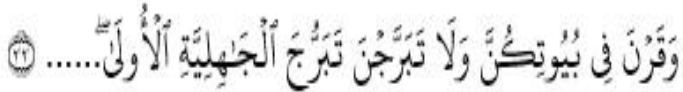

Artinya : dan hendaklah kamu (wanita) tetap berada di rumahmu dan janganlah kamu berbias dan berperilaku sebagaimana orang-orang Jabiliyah yang terdabulu.....

3. Hadits Sahih riwayat Bukhari dari Abu Bakrah, Nabi bersabda:

\section{لن يقلح قوم ولوا أمر هم امرأة}

Artinya: "Tidak akan beruntung suatu kaum yang menyerabkan kepemimpinannya pada wanita."

F. Pandangan yang Mengharamkan Pemimpin Wanita

Pandangan yang melarang Pemimpin dari kalangan perempuan berhujjah dengan ayat Al-Quran surah An-nisa ayat 34 dan juga hadits Nabi dari Abu Bakrah. Dari kedua nash tersebut kalangan ahli fiqih salaf, termasuk madzah empat berpendapat bahwa al-imam harus dipegang seorang laki-laki dan tidak boleh diduduki seorang perempuan. Dalam kitab tafsir ibnu kastsir, Imam Ibnu Katsir menjelaskan tentang QS AnNisa 4:34:

Laki-laki merupakan pemimpin bagi wanita, dikarenakan laki-laki lebih utama dari wanita. Itulah yang menjadi dasar kenabian dikhususkan untuk kaum lakilaki begitu juga dengan raja yang agung, begitu juga posisi jabatan hakim dan lain sebagainya, ibnu Abbas berkata Laki-laki adalah pemimpin bagi wanita, maksudnya adalab sebagai amir yang harus ditaati oleh kaum perempuan.
Imam Ar-Razi dalam Tafsirnya satu pendapat dengan pandangan imam Ibnu Katsir: "Keutamaan laki-laki atas wanita timbul dari banyak sisi. Diantaranya merupakan sifat-sifat faktual dan sebagaian yang lain merupakan hukum syariat seperti al-imamah assughro dan al-imamah as-kubro, azan, jihad, dan lain sebagainya". ${ }^{2}$

Namun, menurut imam Wahba Zuhaili berpendapat bahwa dalam permasalahan jabatan hakim atau qadhi, terdapat perbedaan pandangan para ulama fiqih apakah wajib laki-laki, atau boleh perempuan yang menempati posisi ini. Adapun ulama yang berpendapat bahwa seorang wanita boleh menjabat sebagai hakim ataupun qadhi adalah Abu Hanifah, Ibnu Hazm, dan Ibnu Jarir at-Tabari.

Dalam pandangan beberapa ulama kontemporer berpendapat bahwa kepemimpinan wanita adalah dilarang ataupun haram, seperti Abdul Aziz bin Abdullah bin Baz ${ }^{13}$ yang menyatakan dalam fatwanya bahwa wanita dilarang menduduki jabatan tinggi apapun dalam pemerintahan ${ }^{14}$.

Fatwa Ulama Bin Baz tersebut dikarenakan tidak membedakan antara al-wilayah alkhassah dengan riasah ammah yakni alkhilafah al-ammah. Juga, semua posisi

12 Muhammad Ar-Razi, Mafatibul Ghaib, Darul Ihya`At-Turats Arabi, Bairut, h. 70

13 Abdul Aziz bin Abdullah bin Baz adalah mufti kerajaan Arab Saudi yang berfaham ideologi Wahabi dan bermadzhab fiqih Hanbali.

14 Abdullah bin Abdul Azin bin Baz, Majmuk Fatawa Ibn Baz, no. fatwa: 30461, h. I/424. 
jabatan tinggi seperti hakim, menteri, gubernur, dan semua posisi yang membawahi laki-laki haram hukumnya diduduki oleh wanita.

G. Pandangan yang Membolehkan Pemimpin Wanita

Dr. Muhammad Sayid Thanthawi, Syaikh Al-Azhar dan Mufti Besar Mesir, menyatakan bahwa kepemimpinan wanita dalam posisi jabatan apapun tidak bertentangan dengan syariah. Baik sebagai pemimpin negara (al-wilayah al-udzma) maupun sebagai pemimpin di bawahnya. Imam Tantawi menyebutkan dalam fatwanya yang dikutip majalah Ad-Din wal Hayat, bahwa :

Seorang perempuan yang menduduki posisi sebagai seorang kepala negara tidaklah bertentangan dengan syariat disebabkan $\mathrm{Al}$ Quran memuji perempuan yang menempati posisi seperti ini dalam beberapa ayat tentang kisah Ratu Balqis dari Saba. Dan apabila hal tersebut bertolakbelakang dengan syariat, maka pasti Al-Quran akan menerangkan hal tersebut dalam kisab ini. Adapun sabda Nabi Mubammad $S A W$ yang mengatakan bahwa "Suatu kaum tidak akan berdaulat apabila dipimpin oleb seorang wanita" menurut imam Tantawi hadits ini adalah khusus untuk peristiwa tertentu saja yaitu tentang kerajaan Farsi dan Nabi SAW tidak mengatakannya secara umum. Oleh sebab itulah, maka seorang wanita diperbolebkan menduduki posisi jabatan sebagai, menteri, hakim, Anggota lembaga legislative duta besar babkan kepala negara. Hanya saja perempuan tidak boleh menduduki jabatan Syaikh Al-Az̧bar karena jabatan ini khusus bagi laki-laki saja karena ia berkewajiban menjadi imam shalat yang secara syariah tidak boleh bagi wanita. (majalah ad-Din, $1429 \mathrm{H}$ : Hal 80).

Pendapat ini disetujui oleh Yusuf Qardhawi. Ia menegaskan bahwa perempuan berhak menduduki jabatan kepala negara (riasah daulah), mufti, anggota parlemen, hak memilih dan dipilih atau posisi apapun dalam pemerintahan ataupun bekerja di sektor swasta karena sikap Islam tentang permasalahan ini sudah jelas bahwa seorang wanita itu memiliki kemampuan yang sempurna. ${ }^{15}$

Kepemimpinan seorang perempuan menurut Imam Ali Jumah dalam berbagai jabatan penting telah sering terjadi dalam sejarah peradaban Islam. Ada sekitar 90 orang perempuan pernah menjabat dalam posisi penting yaitu sebagai kepala daerah dan hakim khususnya di era Khilafah Utsmaniyah. Menurut Imam Ali Jumah, keputusan seorang perempuan untuk menempati posisi jabatan publik merupakan keputusan pribadi antara dirinya dengan suaminya.

H. Syarat Perempuan Bekerja di Luar Rumah

Kebolehan seorang perempuan menjabat di posisi penting dalam suatu lembaga pemerintahan maupun di lembaga swasta bukanlah semata-mata tanpa syarat. Agama Islam telah mmbuat rambu-rambu yang harus dipatuhi atas setiap

15 Yusuf Al-Qordhawi, Fiqih Negara, Robbani Press, Jakarta, 1997, h. 80 
keputusan yang diambil oleh setiap muslim dan muslimah. Imam Yusuf al-Qardawi menyatakan bahwa ada tiga syarat yang harus ditatai oleh kaum wanita yang ingin bekerja di luar rumah:

1. Pekerjaan itu tidak dilarang syariah. Seorang perempuan tidaklah boleh melaksanakan pekerjaan yang diharamkan syariat sebagaimana hal itu juga dilarang bagi laki-laki.

2. Pekerjaan yang dilakukan hendaknya tidak meniadakan tugas wanita yang utama yaitu sebagai istri dengan melaksanakan hak-hak rumah tangga dan sebagai ibu dalam memenuhi hak-hak anak.

3. Berpegang teguh pada etika Islam. misalnya tata cara, berpakaian, berjalan, keluar rumah, berpakaian, menjaga gerak geriknya dan dalam berbicara. Makanya seorang perempuan dilarang keluar tanpa memakai pakaian muslimah, atau memakai parfum yang berlebihan agar wanginya tercium oleh kaum lakilaki.

\section{Kesimpulan}

Dari uraian di atas, terdapat kesepakatan ulama fiqih (ijmak) dari keempat madzhab dan lainnya, salaf dan kontemporer, bahwa perempuan tidak boleh menduduki jabatan al-kbilafah alammah atau al-imamah al-udzma. Akan tetapi, tentang defenisi kedua istilah ini terdapat perbedaan pendapat ulama. Kebanyakan para ulama mengartikan kata al-imamah al-udzma atau al-kbilafah al-ammah sebagai kepala negara atau seorang pemimpin yang membawahi wilayah Islam di seluruh penjuru dunia seperti yang terjadi pada zaman khulafaur rasyidin, kbilafah Abbasiyah dan Umayyah. Pada umumnya Ulama fiqih klasik melarang perempuan menjadi hakim, kecuali Ibnu Hazm, Ibnu Jarir At-Tabari dan imam Abu Hanifah mereka membolehkan perempuan menduduki posisi apapun. Pandangan ketiga ulama terakhir ini menjadi salah satu alasan ulama kontemporer atas bolehnya wanita menjabat posisi apapun asal memenuhi syarat.

Ulama yang yang melarang perempuan menjadi kepala negara menganggap seluruh negara muslim saat ini termasuk dalam kategori al-wilayah alammah yang pemimpinnya disebut alimamah al-udzma. Makanya wanita dilarang menduduki posisi seperti ini. Bagi ulama yang membolehkan, seperti, Yusuf Qardawi, Ali Jumah dan Tantawi, mereka berpendapat bahwa negara yang ada saat ini merupakan salah satu bagian wilayah alias al-wilayah al-khassah, bukan al-wilayah al-ammah dan karena itu boleh dipimpin oleh perempuan termasuk posisi jabatan lain yang berada di bawahnya seperti hakim, menteri, gubernur, DPR, dan lainlain.

\section{Daftar Pustaka}

Abarizan. Wanita, Politik Dan Hokum. Pekanbaru : LPP UIN Suska. 2012.

Al-Qordhawi, Yusuf. Fiqih Negara. Jakarta: Robbani Press. 1997

Gibtiah,M.Ag, 2006, Fiqih Kontemporer, IAIN Raden Fatah Press, cet. 1, Palembang.

Hamid, Samad. Islam Dan Pembaharuan. Surabaya : PT. Bina Ilmu. 1984 
Hawi, Akmal, 2007, Kepemimpinan Dalam Islam, IAIN Raden Fatah Press, cet. 1, Palembang.

Mar`At. Pemimpin dan Kepemimpinan. Jakarta : Challis Indonesia. 2983

Mariana, Anna. Ketika Allab Lebih Menyayangi Wanita. Bandung: Kawan Pustaka. 2011

Mawardi. Al-Ahkam As-Sulthaniyah (Terj). Bekasi. 2012

Muin Salim, Abdul. Konsepsi Kekuasaan Politik dalam Al-Quran. Jakarta : Raja Grafindo. 2002

Pahlawan Kayo, Khatib. Kepemimpinan Islam dan Dakwah. Jakarta : Sinar Grafika Offset. 2005

Sarbini, Amirullah. Cara Mudah Wanita Masuk Surge. Bandung : Fajar Media. 2011

Shihab, M. Quraish, Tafsir Al- Misbah: Pesan, Kesan dan Keserasian Alquran, Jakarta: Lentera Hati, 2006 